\title{
Luisteren naar het rommelen van de vulkaan
}

\author{
Gabriel van den Brink ${ }^{*}$
}

Vrooman, C., Gijsberts. M. \& Boelhouwer, J. (2014). Verschil in Nederland. Sociaal en Cultureel Rapport 2014. Den Haag: Sociaal en Cultureel Planbureau.

Het laatste Sociaal en Cultureel Rapport over verschillen in Nederland brengt - net als eerdere publicaties in deze reeks - een mengeling van goed en slecht nieuws. Het goede nieuws is dat er nog altijd een brede middenklasse bestaat die behoorlijk opgeleid is, die een redelijk inkomen heeft en van een goede gezondheid geniet. Het slechte nieuws is dat zich aan de bovenkant én aan de onderkant van de samenleving twee aparte lagen aftekenen die met de ruggen naar elkaar staan. Dat oefent ook een zekere druk uit op de middenklasse, al was het maar omdat het contrast tussen de weg naar boven en de weg naar onder langzaam maar zeker scherper wordt. Daarmee is de strekking van dit rapport toch explosiever dan men uit zijn conceptuele verfijningen en zorgvuldige bewoordingen zou opmaken.

\section{Innovatieve werkwijze}

Los van zijn maatschappelijke betekenis is Verschil in Nederland in wetenschappelijk opzicht heel relevant. In feite voerde het Sociaal en Cultureel Planbureau (SCP) drie innovaties door.

Ten eerste besteden de auteurs, zeker in vergelijking met eerdere rapportages, ruime aandacht aan theorievorming. Ze schreven niet alleen een hoofdstuk over de vele manieren waarop wetenschappers tegen maatschappelijke verschillen (kunnen) aankijken, maar benoemen ook de sterke en zwakke kanten van die perspectieven. Ze bespreken het werk van grote namen als Weber, Pareto of Bourdieu en stromingen als de neoklassieke school, het functionalisme, het neomarxisme, de moderniseringstheorie, de netwerktheorie, het postmodernisme en de ecologisch-evolutionaire theorie van Lenski. Op basis daarvan formuleren ze een eigen model, bedoeld om de vele verschillen die een moderne samenleving als de Nederlandse kenmerken op een open wijze te benaderen. Ze nemen niet op voorhand aan dat bepaalde verschillen (bijvoorbeeld economische) meer gewicht in de schaal leggen dan andere (bijvoorbeeld etnische). Wel veronderstellen ze vier soorten van kapitaal die iemands levenskansen in positieve dan wel negatieve zin beïnvloeden. Het gaat achtereenvolgens om economisch kapitaal, cultureel kapitaal, sociaal kapitaal en iets wat ze typeren als persoonskapitaal. De analyse heeft tot doel om vast te stellen hoe deze vormen van kapitaal over de bevolking zijn verdeeld, hoe ze op elkaar inwerken en welke vormen van segmentatie daar-

* Prof. dr. Gabriel van den Brink is hoogleraar maatschappelijke bestuurskunde aan de Tilburgse School voor Politiek en Bestuur. 
uit voortvloeien. Ofschoon er wel het een en ander valt af te dingen op dit model (bijvoorbeeld waar het om de werking van instituties gaat: zie onder), valt deze aanpak zeer te prijzen.

Een andere innovatie is dat men voor het eerst onderzoek doet naar de betekenis van lichamelijke verschillen. Het gaat deels om harde kenmerken zoals lichaamslengte of body mass index (BMI), deels om subjectieve zaken zoals aantrekkelijkheid of tevredenheid met het eigen voorkomen. Het rapport toont aan dat dergelijke verschillen een voorname rol spelen, zelfs in situaties die op het eerste oog weinig met iemands uiterlijk van doen hebben. Zo hebben 'knappe mensen' meer kans om te worden uitgenodigd voor een sollicitatiegesprek dan mensen met een gemiddeld uiterlijk. Het omgekeerde effect is nog sterker, want 'lelijke mensen' hebben 2,3 keer zoveel kans op een afwijzing. Deze fysieke verschillen zijn ook van invloed op de kans dat iemand een zeer hoog inkomen verdient. Dat effect is bij vrouwen sterker dan bij mannen: vrouwen met veel persoonskapitaal hebben (gecorrigeerd voor andere verschillen) zelfs 25 keer zoveel kans op een hoog huishoudinkomen als vrouwen die weinig gezond of aantrekkelijk zijn. De auteurs concluderen dat iemands uiterlijk ('esthetisch kapitaal') een grote invloed op zijn of haar kansen in het leven heeft, zelfs wanneer men dat met andere verklarende factoren als geslacht, etniciteit of opleiding vergelijkt. Hoewel de meeste Nederlanders zich daarvan bewust zijn (ze besteden niet voor niets zoveel tijd en geld aan uiterlijke verzorging), is dat onderwerp nog vaak taboe. Zo zullen collega's elkaar niet snel aanspreken op hun kleding of gedrag. Alleen tegen mensen met een uitkering durft men te zeggen dat afwijkende zaken zoals een onverzorgd uiterlijk of slecht gebit de kansen op een baan verminderen. Aan dat taboe proberen de onderzoekers wat te morrelen.

Een derde innovatie is dat het SCP wil achterhalen hoe het functioneren van die verschillen door de bevolking wordt ervaren. Het gaat niet alleen om het vaststellen van een reeks objectieve scheidslijnen die het samenleven in Nederland feitelijk beïnvloeden, maar ook om de subjectieve manier waarop allerlei groepen die beleven, waarderen of aanvoelen. Bij het vorige onderwerp ligt die aandacht voor de hand: zaken als aantrekkelijkheid, gezondheid of zelfvertrouwen zijn nu eenmaal sterk subjectief. Er zijn echter goede redenen om ook te kijken naar de gevoelens die met verschil in rijkdom, in leeftijd of in politieke denkbeelden verband houden. Dat levert soms verrassende inzichten op. Zo blijkt dat wij ons in Nederland nauwelijks zorgen maken over verschil in opleiding - hoewel dat tot een reeks zorgelijke verschijnselen leidt. Er zijn eveneens verschillen die feitelijk meevallen, maar in de publieke meningsvorming worden uitvergroot, zoals de wijze waarop jongeren en ouderen tegen elkaar aankijken. En soms zijn er verschillen waar de ene groep zich niets bij kan voorstellen, terwijl de andere daar juist zwaar aan tilt. Dat doet zich - zoals het debat over Zwarte Piet heeft laten zien - vooral bij vormen van discriminatie voor. Zelf denk ik dat we verder moeten gaan door ons te richten op het patroon van normen of verwachtingen dat in elke 'beleving' van maatschappelijke verschijnselen tot uiting komt. De vraag in hoeverre mensen moeite hebben met een bepaald verschil hangt immers sterk af van de waarden die ze aanhangen. Maar dit neemt niet weg dat de onderzoekers 
lof verdienen voor het feit dat ze ook de subjectieve ervaring van maatschappelijke verschillen in kaart hebben gebracht.

\section{Belangrijke bevindingen}

In de ideale wereld zou de indeling van een Sociaal en Cultureel Rapport door de dimensies van het theoretische model worden bepaald. Maar dat roept waarschijnlijk te veel praktische bezwaren op. In elk geval liet men zich bij de weergave van empirische bevindingen vooral leiden door de sectorale indeling die het SCP nu eenmaal kent. De hoofdstukken 2-9 zijn dan ook gewijd aan het onderwijs, financiële ongelijkheid, lichamelijke kenmerken, verschillen van politieke aard, leeftijdsverschillen en spanning op basis van etniciteit. Ik beperk me tot het noemen van een paar opmerkelijke uitkomsten.

Zoals bekend nam de onderwijsparticipatie de afgelopen decennia enorm toe. Terwijl midden jaren vijftig van de vorige eeuw nog maar 6 procent van de jongeren hoger onderwijs volgde, was dat een halve eeuw later 36 procent. Mede daardoor kreeg de Nederlandse maatschappij alle trekken van een meritocratie. Zaken als inkomen, invloed of sociale status zijn niet langer afhankelijk van het milieu waarin men geboren wordt, maar van de verdiensten die men door eigen inspanning verworven heeft. Het onderwijs speelt daarbij een cruciale rol. Ofschoon er tekenen zijn dat een verdere meritocratisering op haar grenzen stuit, is duidelijk dat verschil in opleiding op tal van levensgebieden verstrekkende gevolgen heeft. De aard van iemands beroepsuitoefening hangt voornamelijk van zijn of haar diploma af en dat gaat ook op voor de hoogte van het inkomen. Verder zijn er aanzienlijke verschillen in levensverwachting. Vergeleken met hoogopgeleiden lijden Nederlanders met een lage opleiding vaker aan kwalen als een hoge bloeddruk, overgewicht, roken en zwaar alcoholgebruik. Als gevolg daarvan leven de laatsten gemiddeld zes jaar korter dan Nederlanders met een hoge opleiding. Kijkt men naar de jaren zonder chronische ziekten of lichamelijke beperkingen, dan pakt het onderscheid nog forser uit en wel in die zin dat hoogopgeleide Nederlanders zo'n achttien jaar langer in een goede gezondheid kunnen doorbrengen dan degenen die maar weinig opleiding gevolgd hebben. Een interessante vraag is uiteraard hoe Nederlanders tegen deze verschillen aankijken. Worden ze aanvaard, roepen ze verontrusting op of geven ze aanleiding tot conflicten? Volgens de auteurs komt vooral het eerste voor. In feite worden meritocratische idealen en verwachtingen door vrijwel iedereen aanvaard. De meeste burgers vinden het volstrekt normaal dat mensen die zich in onderwijs en op andere levensgebieden inspannen daarvoor op den duur worden beloond. Ofschoon velen vrezen dat onderwijs in de nabije toekomst minder zal opleveren dan in de voorbije decennia, wordt het belang van een goede opleiding alom erkend. Het risico dat selectie via onderwijs in combinatie met homogamie naar opleiding uiteindelijk tot gescheiden werelden van hoog- en laagopgeleiden leidt, wordt niet echt gezien.

Wat zegt dit rapport over de manier waarop verschillen naar inkomen en vermogen doorwerken? De onderzoekers constateren een lichte toename van de ongelijkheid naar inkomen, maar ze vinden weinig aanwijzingen dat de kloof tussen 
vermogende en niet-vermogende burgers aan het groeien is. Dat komt mede door het toegenomen bezit van eigen woningen. Mensen die er financieel goed bij zitten, beschikken doorgaans ook over andere soorten kapitaal: ze zijn gemiddeld gezonder, ze blijken aantrekkelijker, ze hebben meer sociale contacten en voeren een meer luxe levensstijl. Dit alles onderstreept nog eens dat de verschillen naar inkomen, vermogen en bezit er wel degelijk toe doen. Toch lijkt dat soort verschillen geen urgent probleem te vormen. Er is hooguit een zekere ambivalentie merkbaar. Enerzijds is een meerderheid van de bevolking voorstander van kleine verschillen naar inkomen. Anderzijds speelt deze voorkeur minder sterk mee wanneer het om vermogens gaat. Daar leggen veel (beter gesitueerde) Nederlanders een meritocratisch ethos aan de dag, in de zin dat ze weinig moeite hebben met de rijkdom die iemand door eigen inspanning verworven heeft. Dat geldt voor succesvolle ondernemers in het bedrijfsleven, maar ook voor mensen die met 'slim zakendoen' of door een erfenis hun vermogen uitbreiden: ze kunnen door de bank genomen in Nederland op waardering rekenen. Een belangrijk punt is dat deze ongelijkheid niet ten koste van gewone mensen mag gaan. Verreweg de meeste Nederlanders maken bezwaar tegen het idee dat vermogende mensen op snellere of betere gezondheidszorg kunnen rekenen. Men verzet zich eveneens tegen de mogelijkheid dat ze meer invloed op de politiek hebben of dat hun kinderen beter onderwijs krijgen.

Zoals bekend, werken etnische verschillen sterk in de arbeidsmarkt door. Migranten hebben minder vaak werk of ze hebben werk van een lager niveau, hun inkomens zijn relatief laag, ze zijn eerder aangewezen op een flexibel contract en zitten sneller bij of onder de armoedegrens. Mede daardoor kwam het effect van de crisis extra hard aan. Behalve op economisch gebied werken etnische verschillen ook op sociaal gebied door. Een grote meerderheid van de Turken en Marokkanen is vooral op de groep van herkomst gericht. Van de desbetreffende jongeren voelt ongeveer de helft zich geen Nederlander. Dat blijkt ook bij morele en culturele vraagstukken. Met betrekking tot de positie van vrouwen, het accepteren van homoseksualiteit en de plaats van het geloof in de samenleving denken veel Turkse en Marokkaanse burgers conservatief. Vergeleken met christenen onderschrijven praktiserende moslims vaker het idee dat joden niet te vertrouwen zijn. Van de andere kant wordt er vaak gediscrimineerd. Bij sollicitaties worden allochtone Nederlanders minder snel uitgenodigd voor een gesprek, ook al beschikken zij over genoeg ervaring en opleiding. Dat alles zorgt uiteraard voor spanningen, en de auteurs verwachten niet dat deze de komende periode zullen afnemen. Bijna de helft van de autochtone bevolking gelooft dat de levenswijze van moslims en die van West-Europa niet samengaan. Opmerkelijk is dat vooral beter opgeleide allochtonen bepaalde vormen van discriminatie aan de kaak stellen. Men spreekt in dat verband ook wel van een integratieparadox: het zijn veelal jonge en goed geïntegreerde leden van een migrantengroep die zich verzetten tegen ongelijke behandeling of uitsluiting. Zij willen zich niet langer als tweederangsburger laten bestempelen en eisen een eigen plaats in Nederland op.

Tot slot enkele verschillen op politiek en cultureel vlak. Er blijkt een relatie te zijn tussen politiek zelfvertrouwen en ideeën over Europese eenwording of multiculturele samenleving. Burgers die moeite hebben met globalisering, vinden vaak dat 
hun invloed zeer gering is en dat politici niet luisteren. Burgers met een open houding tegenover culturele verschillen tonen meer zelfvertrouwen. Ook op dit punt is er een duidelijke samenhang met opleiding. Onvrede met de politiek komt relatief vaak onder laagopgeleiden voor. Terwijl hoogopgeleide burgers gemiddeld 33 procent van de bevolking uitmaken, vormen ze 59 procent van de groep met de minste onvrede en slechts 16 procent van de groep met de meeste onvrede. Voor burgers met een geringe opleiding geldt het omgekeerde. Daarnaast is er een relatie met leefstijl en beroepsniveau. Mensen met een bescheiden beroep en een weinig luxueuze levensstijl zijn eerder ontevreden over de politiek. Zij die veel aan het culturele leven deelnemen, verre vakanties boeken of vaak uit eten gaan, klagen minder over politieke onvrede. Die samenhang kan wellicht worden verklaard vanuit een grotere vertrouwdheid met datgene wat er in de politiek gebeurt: ze merken dat mensen zoals zij een behoorlijke invloed op de gang van zaken in het land hebben. Of ze kunnen zich beter vereenzelvigen met mensen die in de sfeer van bestuur en politiek werken. Ze brengen meer vertrouwen in bestuurlijke processen op omdat deze vaak door 'ons soort mensen' geleid worden. Nederlanders die niet behoren tot de inner circle van bestuur of politiek, nemen meer conflicten in de samenleving waar. Bijvoorbeeld conflicten tussen machthebbers en gewone burgers of tussen autochtone en allochtone groepen in de bevolking. Dat zijn de spanningen die sinds de komst van Pim Fortuyn aan het licht traden en die maken dat velen zich afkeren van het politieke bedrijf.

\section{Segmentatie van Nederland}

Tot zover een synopsis van belangrijke bevindingen. De conclusie is dat de Nederlandse maatschappij meerdere domeinen kent waar vele verschillen optreden en dat er bovendien vele samenhangen tussen al die verschillen bestaan. Daarmee biedt Verschil in Nederland een rijk tableau van de enorme variatie die het moderne leven kenmerkt. Maar tot welke diagnose leidt dit? Wat is het beeld dat aan het slot van deze exercitie resteert?

Een van de doelen die het SCP zich met dit rapport stelt, is te komen tot een meer precieze segmentatie van de samenleving. Daartoe onderwerpt men de desbetreffende gegevens aan een latente klassenanalyse. Dat is een statistische techniek waarbij de respondenten worden verdeeld over groepen waarin een zo goed mogelijke samenhang van alle kenmerken ontstaat. Het resultaat is een reeks van zes segmenten die elk een eigen naam krijgen. Het gaat achtereenvolgens om de gevestigde bovenlaag (15 procent van de bevolking), jonge kansrijken (13 procent), werkende middengroep (27 procent), comfortabel gepensioneerden (17 procent), onzekere werkenden (14 procent) en ten slotte een segment dat wordt aangeduid als het precariaat (15 procent). In kwantitatieve zin valt daar weinig op af te dingen, maar de grote vraag is hoe men op basis van die segmentatie tot een overtuigend beeld komt. Twee gedachten wijst het SCP nogal nadrukkelijk af. Enerzijds het idee van een brede stabiele middenklasse waarbij randverschijnselen aan de onderkant en bovenkant weinig relevant zijn. Anderzijds het idee van een gepolariseerde samenleving waar twee klassen tegenover elkaar 
komen te staan en de middenklasse verdwijnt. Uiteindelijk kiest men - heel Nederlands - voor een compromis waarbij men beide gedachten met elkaar mengt. Het daaruit voortvloeiende beeld lijkt, zoals het SCP zelf opmerkt, op een sandwich: aan de bovenkant en de onderkant van de sociale hiërarchie is sprake van min of meer harde klassenvorming en daartussen zitten vier lagen die samen ongeveer 70 procent van de bevolking omvatten en waarin zich uiteenlopende spanningen of problemen voordoen. Aan het slot van zijn voorwoord spreekt de directeur van het SCP over een 'zachte' tweedeling die soms tot ongemakkelijke tegenstellingen leidt maar geen simpele polarisatie is tussen haves en havenots. Die conclusie zal in Den Haag niet slecht vallen, want ze biedt voor elk wat wils. Het rapport is bruikbaar voor mensen die denken dat we naar een harde tweedeling gaan en ook voor mensen die denken dat het in Nederland reuze meevalt. Aan dat politieke aspect ga ik voorbij. Mijn bezwaren tegen het eindbeeld zijn empirisch en theoretisch van aard.

De empirische moeilijkheid is dat het Sociaal en Cultureel Rapport van 2014 op vele plaatsen laat zien hoe groot de grote spanningen zijn. Daarbij gaat het niet alleen om wrijving tussen allochtone en autochtone Nederlanders, maar vooral om de incongruentie van 'mensen die het in dit land voor het zeggen hebben' en de rest van de bevolking. Het rapport constateert dat het gedrag van de Nederlandse elite de nodige weerzin oproept. Tal van burgers storen zich aan een groep van toonaangevende en machtige Nederlanders die zich in moreel opzicht superieur acht. Die groep denkt vooral aan zichzelf en zet zich onvoldoende voor de publieke zaak in. Vele respondenten vinden dat het de verkeerde kant op gaat met Nederland en van hen zegt maar liefst 85 procent dat de elite daarvoor verantwoordelijk is. Het gaat nu even niet om de vraag of dat objectief bezien klopt (vermoedelijk niet), maar om de vraag wat dit over de ervaringswereld van Nederlandse burgers zegt. Die wereld moet beter worden geduid, temeer omdat het SCP inmiddels beseft dat subjectieve oordelen voor het politieke bedrijf zeer relevant zijn. De urgentie daarvan wordt onvoldoende erkend. Overigens geldt dat in nog sterkere mate voor de elite zelf, die in een apart hoofdstukje aan het woord komt. De daar verzamelde stemmen stellen in elk opzicht teleur. De enige die bereid is tot zelfkritiek is Herman Wijffels. Voor het overige wijzen uitlatingen van de elite op een vorm van zelfgenoegzaamheid die zo niet in moreel, dan toch in politiek opzicht zeer bedenkelijk is. De auteurs van het rapport zijn zich daarvan bewust. $\mathrm{Ze}$ maken korte metten met het veelgehoorde verweer dat de elite door de opkomst van het populisme of het functioneren van de media onder druk staat. 'Dit alles op het conto van de opmars van het populisme in de politiek en de media schrijven, is de oorzaak met het gevolg verwarren', schrijft men terecht. Maar het is te weinig en ook te zwak. De Europese geschiedenis leert dat maatschappelijke stabiliteit op termijn alleen mogelijk is als de bovenkant op een of andere wijze engagement met de onderkant toont. In die zin zou een nieuw sociaal contract tussen kansrijke en kansarme burgers wenselijk zijn. Vooralsnog houdt de elite zich doof. Maar de oplettende waarnemer hoort hoe de vulkaan aan het rommelen is.

Mijn tweede bezwaar tegen het beeld van de sandwich is meer theoretisch van aard. Ik zou meer systematisch aandacht willen voor de processen van selectie die 
voortvloeien uit het functioneren van onze grote instellingen. Scholen, bedrijven en andere organisaties zijn in de loop der jaren hogere eisen gaan stellen aan eventuele deelname. Bijgevolg vallen er steeds vaker mensen af. $\mathrm{Nu}$ komt het thema van de selectie in het rapport op enkele plaatsen aan bod. Bijvoorbeeld als men schrijft over de keuze van een vervolgstudie of waar het over discriminatie op de arbeidsmarkt gaat. Maar begrippen als variatie en selectie vormen geen wezenlijk bestanddeel van het theoretische model, met als gevolg dat het sorteren van individuen met hun diverse kenmerken of vermogens onvoldoende uit de verf komt. Individuele burgers hebben altijd met een mix van goede en kwade kansen van doen. Maar die pakken door de wijze waarop gezinnen, scholen, sollicitatieprocedures, rechtspraak, politieke processen of beeldvorming in de media functioneren zeer ongelijk uit. De vraag hoe iemand in de loop van zijn leven door allerlei vormen van selectie komt, is zeer bepalend voor de latere levenskansen. We mogen (juist doordat de samenleving sterk in het teken van een meritocratie kwam te staan) steeds minder aannemen dat het met ons leven min of meer vanzelf goed komt. Mensen komen sneller terecht in een opwaartse dan wel een neerwaartse spiraal. Bijgevolg wordt het verschil tussen geslaagde levens en mislukte levens steeds duidelijker. Dat is met name voor de middenklasse een bang avontuur. Wie bepaalde capaciteiten heeft, zijn best doet en voldoende hulp krijgt, zal de weg omhoog vinden en eindigt eventueel in de gevestigde bovenlaag. Maar wie weinig capaciteiten heeft, zich minder inspant en slecht wordt geholpen, zakt op een zeker moment door het ijs en belandt als alles fout gaat in het precariaat. Dat heeft op termijn ook gevolgen voor de maatschappelijke stabiliteit. Het SCP stelt dat men dit niet kon onderzoeken door het ontbreken van longitudinale data. Maar wat we wel weten is dat de eisen op domeinen als paarvorming, gezinsleven, onderwijs of arbeidssituatie de afgelopen decennia geleidelijk omhoog gingen, terwijl de processen van selectie zeker niet minder werden. Het gevolg is dat de middenklasse mentaal in toenemende mate onder spanning staat. Hoewel er nog geen sprake is van een echte tweedeling, hebben leden van de middenklasse goede gronden om te vrezen dat ze in de nabije toekomst voor zo'n tweedeling komen te staan. Misschien niet op collectief, maar wel op individueel niveau en misschien niet als het om ons eigen leven, maar wel als het om dat van onze kinderen gaat. 